\title{
Agricultural Mechanization as an Expansion Factor of Cropland in Benin: The Case of Tractors
}

\author{
Ichaou Mounirou $^{1,2}$ \\ ${ }^{1}$ Doctor Lecturer-Researcher at the Faculty of Economics and Management (FASEG) of the University of \\ Parakou, Benin \\ ${ }^{2}$ Assistant Professor of CAMES Universities, Laboratory of Public Economy (LEP), Benin \\ Correspondence: Ichaou Mounirou, Doctor Lecturer-Researcher at the Faculty of Economics and Management \\ (FASEG) of the University of Parakou, Benin. E-mail: ichaou_bassir@yahoo.fr
}

Received: November 21, 2017 Accepted: December 8, 2017 Online Published: July 19, 2018

doi:10.5539/sar.v7n4p1 URL: https://doi.org/10.5539/sar.v7n4p1

\begin{abstract}
We propose in this paper a methodology based on the vector error correction (VCE) model. This modeling approach makes it possible to use a large database to model the impact of agricultural mechanization on cropland in Benin. The results of the VEC model estimates confirm a positive relationship between agricultural mechanization and the areas planted of paddy rice, millet and yams. Moreover, the findings suggest that agricultural mechanization is still far to boost the land uses of cotton, maize and cassava, despite the importance of cotton in the Beninese economy on the one hand, and the key roles of maize and cassava in diet in Benin, on the other hand. Agricultural mechanization is far from being a reality in Benin's agricultural sector to the extent that public agricultural investments are below the Maputo agreements (Note 1). An effective agricultural mechanization must opt for cereals whose investments in agricultural machinery are less expensive compared to cotton. This strategy of agricultural mechanization makes it possible to better ensure food security, unlike the intensive cotton production, whose terms of trade are always unfavorable and dependent on subsidies from the North.
\end{abstract}

Keywords: agricultural tractors, area planted, VEC model

\section{Introduction}

In Benin, the agricultural sector occupies more than $85 \%$ of the active population and contributes $79 \%$ to the gross domestic product (GDP) in 2015, while this contribution amounted to 59\% over the period 1990-2009. In addition, agriculture accounts for more than $90 \%$ of export earnings (MAEP, 2015). The main crops produced are cereals and cotton. Cotton that is the main cash crop, contributed up to 2007 to $80 \%$ of export earnings (Note 2). The most important food crops are maize, millet, sorghum, cassava, yam and cowpea. At the same time, these food crops represent Benin's consumption habits. The challenges of agricultural production remain significant, because only $40 \%$ of the arable land is cultivated and the productivity levels are still low. The growth rate in the agricultural sector was $4.58 \%$ between 1980 and 1989, 5.1\% between 1990 and 2005 and $4.3 \%$ between 2006 and 2009. (Note 3)

The Beninese agriculture is characterized by the use of traditional tools (daba, machete and other hand tools). The operations are $76 \%$ manual, $23 \%$ with animal traction and only $1 \%$ is motorized (PPMA, 2015). In addition, barely half of the agricultural products are covered by adequate transport services. Similarly, post-harvest facilities (storage, conservation, processing and marketing) remain rudimentary. In this context, the government set up in 2009 the Agricultural Mechanization Promotion Program (PPMA). This was within the framework of the vision expressed in the Strategic Development Objectives (OSD): "To make Benin, a dynamic agricultural power by 2015 , competitive, attractive, respecting the environment, creating wealth meeting the socio-economic development needs of the population". To achieve this, the Ministry of Agriculture, Livestock and Fisheries (MAEP) has developed a national strategy of agricultural mechanization which aims to achieve a mechanization of $20 \%$ of land use by 2015 through public-private partnership. This is why the PPMA was set up in 2009. A program that has made it possible today to acquire 450 tractors, 550 tractor plows, 1003 -tonne agricultural trailers, 124 5-tonne agricultural trailers and 250 tillers. 
Despite the efforts of agricultural mechanization in Benin, paddy rice production systems are largely dominated by small family-type farms. In addition to this family-owned rice cultivation, there are developed areas with partial or total water control. The majority of the paddy rice farms are concentrated in the lowland either developed or not. However, paddy rice is grown in plateaus and floodplains, especially with the advent of NERICA varieties. On the strength of these investments in agricultural mechanization, statistics from the MAEP (2014) show that the rate of manual plowing and plowing operations amounted to $84 \%, 12 \%$ and $4 \%$ for motorized and animal traction, respectively. This motorization is mainly practiced on the irrigated perimeters with collective management of Dévé (150 ha), Koussin-Lélé (250 ha) and Malanville (560 ha).

But since 2009, Benin through the PPMA has invested on its own funds tens of billions of CFA for the promotion of agricultural mechanization through the importation of several hundreds of tractors, tillers with their accessories (plows, mowers, trailers), and about ten harvesters. Cereals and pulses recorded increases in both land uses and production. However, for cereals, the land use and production of paddy rice, compared to those of 2014, decreased by $3.98 \%$ and $2.56 \%$, respectively. Compared with the average of the last five years, this same crop has achieved a rise of $28.45 \%$ in the area planted and $35.23 \%$ for production. We also note that for legumes, peanuts recorded a $2.99 \%$ and $3.62 \%$ decrease in land use and production compared to 2014, respectively (ONASA, 2016). Mechanization has the potential to increase production, improve timing of operations, expand energy application to improve crop processing, irrigation and infrastructure, offset shortages and labor-saving, which is particularly important when the aging and feminizing workforce continues to use mainly the manual hoe for primary cultivation.

Despite these perceived benefits and the fact that animals were largely replaced by tractors in the United States and Western Europe in the 1950s there were still advanced arguments to urge caution in the developing world (FAO, 2008). The main concern in this article is the effect of mechanization on agricultural land uses in Benin. What are the lands uses that benefit from mechanical innovations in Benin?

\section{Theoretical and Empirical Literature Review}

The mechanization of production is ultimately based on economic criteria and is part of the economic revolution of agricultural trade. Thus, it can be argued that the accelerated mechanization of agriculture is transforming the economic structure of the industry, as well as the particular agricultural units that make it up. Therefore, mechanization plays a key role in the agricultural regrouping. The farmer can indeed, equipped with modern equipment, work alone on large surfaces. In addition, many already highly mechanized farmers will find that they can, with their current equipment, cultivate a large area. It is postulated, moreover, that mechanization acts as a fundamental determinant of the increase in agricultural land use. The answer depends on the validity of two hypotheses: a) farmers (especially the small ones) are forced to abandon their farm, because the mechanization is no longer profitable on a small scale; (b) although farmers who immobilize funds to acquire a whole range of machines cannot do otherwise than to mechanize themselves to excess and are therefore obliged to enlarge their production base in order to extract from their machines an efficient level of output. These two hypotheses are far from being verified. These two hypotheses are based on a double premise: first, the machines being relatively massive, they cannot always be proportionate to the arable surface of the farm. Secondly, modern machines tend to combine several spots into one, which is more and more important, rather than just mechanizing such a particular task. Consequently, in order to make farming methods effective, with a small staff, it is necessary to bring the required machines at great expense. It may be well thought that these pressures are being felt by farmers on very small farms and are pushing farmers to expand their farms or close their businesses, but it is hard to believe that these problems are found on farms covering up to 640 acres, many of which have been amalgamated on the prairies.

In its broadest sense, mechanization is the set of tools and machines that can be used in manual, hitched, or motorized cultivation for all operations from clearing and land management to processing (Brordet et al., 1988). More specifically, mechanizing agriculture means using machinery and using more energy, especially to increase labor productivity and, often, to achieve results that are out of proportion to the results of this work (FAO/UNIDO, 2008).

Agricultural machinery refers to the various machines used in agriculture (tractors, combine harvesters, etc.), as well as, by extension, all the political, economic or industrial doctrines aimed at developing the use of these machines to replace the labor and/or to increase agricultural productivity. According to the FAO, (2008), agricultural mechanization in the broad sense can be defined as all agricultural equipment used for agricultural purposes: - off the farm and in this case it includes all agricultural work development and production from tillage to harvesting, both on-farm and in all the technology for animal production and primary processing of 
agricultural products. According to the FAO (2014), the mechanization of agriculture has made it possible to extend cultivable areas and increase yields, essentially improving the precision of farming techniques. In fact, most farmers in developing countries spend more, every year, on energy inputs, fertilizers, seeds or agrochemicals. According to Yurdakul (1994), there are three indicators for measuring the level of agricultural mechanization in a country: (i) traction power per ha; (ii) the number of tractors per 1000 ha; (iii) the SAU per tractor. FAO (2014) summarizes the main reasons for replacing, for crop production, muscle energy (human or animal) by tractors: (i) the possibility of extending the cultivated area; (ii) the ability to perform the operations at the right time to maximize production potential; (iii) the multifunctional characteristics of mechanization, as tractors can be used not only for agricultural production, but also for stationary transport and feeding, as well as for the improvement of infrastructure (irrigation and drainage canals and road works); (iv) mechanization can compensate for seasonal labor shortages (or, indeed, free labor for more productive work), and (v) mechanization reduces the arduousness associated with the use of human muscular strength for difficult tasks such as hoeing by hand for the first plowing. This is particularly important in tropical regions, where high temperatures and high humidity (possibly associated with inadequate feeding) make manual work extremely difficult.

The strategic problem that the farmer must solve is the adjustment of needs-production income. Thus, in traditional agriculture, where most of the food needs are met by self-production, the question of the increase of production is acute. In this sense, mechanization (animal traction and/or tractors), encouraged by the need to cultivate large areas in the face of ever-increasing food needs and low yields, has become unavoidable. Well introduced and accepted, it has made it possible, according to Campagne (1989), to develop forms of crop-livestock association favoring yield improvement by the transformation of manure techniques. Agriculture must move towards new alternatives to meet the different demands. Thus, cultural intensification becomes a necessity and one of the main alternatives is to mechanize (Campagne, 1989). The work of Havard et al. (1988) shows that agricultural mechanization is essential to increase production but also productivity. This agricultural mechanization requires the necessary investments to maintain the level of mechanization. Taking the number of four-wheeled tractors as an indicator of the progress of mechanization, FAO (2008) reports the following trends over the last 40 years: in Asia, the number of tractors increased five-fold between 1961 and 1970 from 120,000 to 600,000 units. Later, the number has increased tenfold to reach 6 million units in 2000. Since then, these figures have continued to increase, especially in India, which had 2.6 million tractors in 2010 - FAO (2013a) -and China, which exceeded 2 million units in 2008 - FAO (2013b); in Latin America and the Caribbean, the number of tractors was multiplied by 1.7 between 1961 and 1970, from 383000 to 637000 units, then tripled to 1.8 million units in 2000; in the Near East, the situation is similar to that of Latin America, with the number of tractors having doubled from 126000 to 260000 units between 1961 and 1970, before being multiplied by 6.5 to 1, 7 million units in 2000; in sub-Saharan Africa, the trend has been quite different. In 1961, the number of tractors used was higher than in Asia and the Near East (172,000 units). Later, their number slowly increased to a peak of 275,000 units in 1990, before falling back to 221,000 units in 2000. Despite this adoption of agricultural mechanization in some parts of the world, concerns remain mainly about the surge in world population (now at 7.31 billion) is well on track to reach 9 billion in 2050 and to exceed 11 billion by the end of the century.

The 500 million small farms in the world currently produce about $80 \%$ of our food and they will have to bear the brunt of the necessary increase of more than $60 \%$ of the food production that will have to be realized in 2050 compared to the levels of 2007 (FAO, 2011). Currently, many of these small farms have limited access to production inputs, including mechanization, and thus achieve low levels of productivity. They also have fewer opportunities to access markets to take advantage of the many value-added activities that more developed food systems can provide. At the same time, the rural population is expected to decline as people, especially healthy young people, migrate to urban centers in search of a life less hard than agriculture can offer; there is also a growing feminization of peasant agriculture, particularly in sub-Saharan Africa, with farm control being increasingly left to women. The potential of rural mechanization for women in rural areas and the development of local economies are often underestimated. Currently, half of the population in developing countries is working in the rural sector, a figure that is expected to fall to $30 \%$ in 2050. Given the current importance of human muscle energy in small farms, the consequences of the limits of this type of energy are severe (Sims and Kienzle, 2015). The adoption of agricultural mechanization has led to an increase in smallholder productivity that must be achieved in a sustainable way, as the story of the Green Revolution (GR) model tells us. By the 1950s and throughout the 1960s, GR caused changes in crop species and agricultural practices worldwide (Royal Society, 2009). The production model, initially focused on introducing high-yielding varieties of wheat, rice and maize into high-potential regions (Hazell 2008, Gollin et al. 2005), had as aim homogeneity: the choice was made of varieties with genetic uniformity, cultivated with large volumes of complementary inputs in various forms (irrigation, fertilizers and pesticides), which often replaced more ecological practices. Fertilizer use replaced soil 
quality management, while herbicides offered an alternative to crop rotations for weeds, pests and diseases (Tilmann, 1998). Havard et al. (1988) note that for decades, mechanization has been part of agricultural policies. The author concludes that a timid intensification did not have a major effect on rain-fed cereal crops. Downing attempted to determine the extent to which the use of machinery had contributed to improved crop yields. Among cereals, he concludes, it is probably oats that have benefited the most from the benefits of mechanization. The improvement of potato crops would be directly related to the adoption of new machines allowing a better use of the fertilizer and the improvement of the equipment of plowing, planting and harvesting.

The empirical review concludes that the adoption of new and improved machines and the new operations made possible have resulted in a more productive agriculture. Agriculture was formerly only a profession characterized by the heavy and heavy foot of the horse pulling its cart and whose pace and pace were almost entirely governed by climatic and biological considerations; today it can hear that it has changed its physiognomy. The modern farmer controls a series of quasi-industrial operations and uses vast sources of mechanical energy and all kinds of machines to accomplish these operations quickly, without depending too much on weather and climatic conditions.

\section{Data Sources and VAR Model Specification}

\subsection{Data Sources}

The paper makes use of secondary data. These data come mainly from the FAO statistical sources and cover the period from 1961 to 2016. These data relate to the number of agricultural tractors and the areas planted for the different crops in Benin. The variables used in this article are: the number of agricultural tractors (lntracg). This variable represents agricultural mechanization and explains the adoption of tractors by producers in Benin. The land uses of cotton (lnsupcot), maize (lnsupma), cassava (lnsupmc), millet (lnsupmils), paddy rice (lnsupriz) and yam (Insupigm) are chosen in this article to the extent to which the production of these crops play a decisive role in the economy, especially cotton, which is the second source of foreign exchange on the one hand, and the others contribute enormously to diet and food security. We postulate in this article that an increase in the number of tractor is likely to induce increase in areas planted.

Table 1. Descriptive statistics of agricultural machineries and land uses

\begin{tabular}{lccccccc}
\hline \multicolumn{1}{c}{ Statistics } & \multicolumn{7}{c}{ Agricultural machineries and land uses } \\
\hline & Lnsupard & Lnsupcot & Lnsupma & Lnsupmc & Lnsuprz & Lnsupmil & Lntracg \\
\hline Mean & 12.6363 & 11.4155 & 13.1188 & 11.7976 & 9.168661 & 10.14968 & 4.57214 \\
Median & 12.64433 & 11.4560 & 13.0539 & 11.6673 & 8.988943 & 10.27461 & 4.53254 \\
Maximum & 12.99203 & 12.9322 & 13.8217 & 12.6002 & 11.21971 & 10.79409 & 5.84354 \\
Minimum & 12.14367 & 9.80818 & 12.4749 & 11.1562 & 7.351158 & 9.193092 & 3.33220 \\
Std. Dev. & 0.179021 & 1.06839 & 0.33386 & 0.43660 & 1.018698 & 0.471428 & 0.54175 \\
Skewness & -0.599150 & 0.038366 & 0.477519 & 0.405979 & 0.227092 & -0.312416 & -0.06601 \\
Kurtosis & 3.490108 & 1.476411 & 2.389276 & 1.744559 & 2.282704 & 1.631485 & 2.485951 \\
Jarque-Bera & 3.771292 & 5.236228 & 2.891431 & 5.029671 & 1.621796 & 5.092309 & 0.633775 \\
Probability & 0.151731 & 0.072940 & 0.235577 & 0.080876 & 0.444459 & 0.078383 & 0.728413 \\
Sum & 682.3649 & 616.4386 & 708.4181 & 637.0725 & 495.1077 & 548.0829 & 246.8958 \\
Observations & 54 & 54 & 54 & 54 & 54 & 54 & 54 \\
\hline
\end{tabular}

\subsection{Econometric Estimates and Policy Implications}

For reasons specific to the size of the data, the maximum lag is fixed at 7. Above 7, the estimates could suffer from a lack of precision. For each value of $\mathrm{p}$ ranging from 1 to 7 , the following model is estimated:

where

$$
Y_{t}=A_{1} Y_{t+1}+A_{2} Y_{t+2}+--+A_{p} Y_{t+p}+\varepsilon
$$

$$
Y_{t}=\left(\text { lntracg }_{t} ; \operatorname{lnsupcot}_{t} ; \operatorname{lnsupma}_{t} ; \operatorname{lnsupmc}_{t} ; \text { lnsupmils }_{t} ; \text { lnsupriz }_{t} ; \operatorname{lnsupigm}_{t}\right)
$$

Then the values of the information criteria are calculated. The results are presented in Tables 2 and 3. Two information criteria (AIC and SC) give the optimal lag of 2. The SC and AIC criteria lead to convergent estimators of $\mathrm{p}$ whereas the AIC criterion gives an efficient estimator of $\mathrm{p}$. The value used is $\rho=2$ because of the length of our series. The search for the number of cointegrating relations was made according to Johansen's approach. The test was carried out with specification 1) that is to neither say, the model without constant neither in the ECM nor in the long term relation, do the series not present a trend. The test is carried out with a lag of 1. 
The results are presented in Table 4 . The trace test indicates the presence of a cointegration relationship at the $1 \%$ level of significance and two relations at the 5\% significance level. As for the test of the maximum eigenvalue, it indicates the existence of a cointegration relation at $1 \%$ and at $5 \%$. The VAR representation is no longer valid; an error-correction model is then used.

In this context, Johansen and Juselius test various hypotheses. First, they present two tests concerning the dimension of the cointegration subspace (test of the trace and test of the maximum eigenvalue). On the other hand, they consider the hypothesis $H_{0}: \mu=\alpha \beta_{0}$, which means that the model is written in fact:

$$
\Delta X_{t}=\sum_{i=1}^{k-1} \Gamma_{i} \Delta X_{t-i}+\alpha\left(\beta^{\prime} X_{t-k}+\beta_{0}\right)+\varepsilon_{t}
$$

That is, the constant actually occurs in cointegration relations, and not in the form of a deterministic trend. Finally, they present linear restriction tests on $\alpha$ and $\beta$, allowing in particular to test if the hypotheses of long-term relations resulting from economic theory are compatible with the results. This method is currently experiencing significant success. It has the advantage of being fairly simple to implement, whether in the estimation or testing procedure Juselius (1990, 1991a) and Johansen and Juselius (1988, 1990, 1991). The results in Table 2 show that all the ADF statistics are lower than the critical statistics of the different thresholds, that after the first differentiation they are thus integrated of order one (I (1)). So we can conclude that there may be a cointegration relationship. For the verification of cointegration, the optimal lag that minimizes the information criteria of AIC (p) and SC (p) are provided in Table 3. This number is equal to one for the variables in this article.

The results of the Granger causality test in Table 5 in first difference indicate whether the addition of one of the seven variables improves the forecast of the number of agricultural tractors, which relies solely on the past evolution of the latter. If this is the case the variable in question includes information on the number of future agricultural tractors. Variables with first difference were used with a maximum lag of 2 years. The hypothesis tested is that of a non-causality of Granger. The rejection of the hypothesis tested is marked with an asterisk. One, two or three asterisks mean that the hypothesis tested is rejected with a significance level of $10 \%, 5 \%$ and $1 \%$, respectively. The test takes place in pairs of variables and without taking into account possible cointegration relationships. The number of agricultural tractors (Intracg) causes the land use of millet (lnsupriz), paddy rice (Insupriz), and yam. We note that there is no causal relationship between the number of agricultural tractors (lntracg) and land uses of cotton, maize and cassava. The direction of causality between the number of agricultural tractors and land use of yam over the period from 1961 to 2016 is not bidirectional. This result is explained by the major role played by yam production in Benin's diet. Agricultural mechanization seems to be used for the production of yam, which looks more profitable than cotton. The number of agricultural tractors does not cause the area planted of maize and cassava, as both crops are produced on almost all land with rudimentary tools.

Table 6 shows a strong correlation between the areas planted of paddy rice, millet, yams and the number of agricultural tractors. On the other hand, there is a weak relationship between the areas planted of cotton, maize, cassava and the number of agricultural tractors. These surprising results indicate that the sown areas of cotton, maize and cassava seem not to benefit from mechanical innovations in Benin. Despite this lack of agricultural mechanization, there are strong relationships between the areas of cotton, maize and cassava. This last result seems to indicate the effects of crop rotations.

Table 2. Results of unit root tests

\begin{tabular}{lllllllll}
\hline \multirow{2}{*}{ Variables } & In level & & In first difference & & Trend & Cte & Lag & order \\
\cline { 2 - 8 } & $\begin{array}{l}\text { Augmented Dickey-Fuller } \\
\text { test statistic }\end{array}$ & $\mathrm{t}$-Statistic & $\begin{array}{l}\text { Augmented Dickey-Fuller } \\
\text { test statistic }\end{array}$ & t-Statistic & & & \\
\hline Lnsupard & -2.917650 & -1.997948 & -2.919952 & $-9.653^{* *}$ & Yes & Yes & 2 & $\mathrm{I}(1)$ \\
Lnsupcot & -2.917650 & -0.815129 & -2.918778 & $-6.173^{* *}$ & Yes & Yes & 2 & $\mathrm{I}(1)$ \\
Lnsupma & -2.919952 & 0.772450 & -2.919952 & $-7.580^{* *}$ & Yes & Yes & 2 & $\mathrm{I}(1)$ \\
Lnsupmc & -2.917650 & -0.797314 & -2.918778 & $-7.722^{* *}$ & Yes & Yes & 2 & $\mathrm{I}(1)$ \\
Lnsuprz & -2.917650 & 0.338691 & -2.918778 & $-7.150^{* *}$ & Yes & Yes & 2 & $\mathrm{I}(1)$ \\
Lnsupmil & -2.919952 & -1.439335 & -2.918778 & $-7.150^{* *}$ & Yes & Yes & 2 & $\mathrm{I}(1)$ \\
Lntracg & -2.918778 & 2.413381 & -2.916566 & $-13.23^{* *}$ & Yes & Yes & 2 & $\mathrm{I}(1)$ \\
\hline
\end{tabular}

** Significant at the 5\% significance level 
Table 3. Choice of optimal lag for the variables of the VAR model

\begin{tabular}{ccc}
\hline Lag & AIC & SC \\
\hline 1 & -25.562 & -22.762 \\
\hline
\end{tabular}

Table 4. Johansen test for the variables of VAR model

\begin{tabular}{lllll}
\hline H0 & Statistique de la de valeur propre maximale & Statistique de la Trace & Valeur critique au seuil de 5\% & probabilités \\
\hline $\mathrm{r}=0$ & 0.863221 & 421.9920 & 334.9837 & $0.0000^{* *}$ \\
$\mathrm{r} \leq 1$ & 0.731021 & 318.5439 & 285.1425 & $0.0009^{* *}$ \\
$\mathrm{r} \leq 2$ & 0.698276 & 150.2617 & 239.2354 & 0.5145 \\
$\mathrm{r} \leq 3$ & 0.610741 & 187.9531 & 197.3709 & 0.1325 \\
$\mathrm{r} \leq 4$ & 0.516908 & 198.8906 & 159.5297 & 0.3746 \\
$\mathrm{r} \leq 5$ & 0.455777 & 101.0580 & 125.6154 & 0.5682 \\
$\mathrm{r} \leq 6$ & 0.363500 & 99.42140 & 95.75366 & 0.7415 \\
$\mathrm{r} \leq 7$ & 0.298668 & 75.92935 & 69.81889 & 0.7999 \\
\hline
\end{tabular}

** Significant at the $5 \%$ significance level

Table 5. Granger causality test

\begin{tabular}{|c|c|c|c|}
\hline \multicolumn{4}{|l|}{ Granger Causality Tests Lags: 2} \\
\hline Null Hypothesis & Obs & F-Statistic & Prob. \\
\hline d(Lnsupigm) does not Granger Cause d(Lntracg) & 54 & 5.23323 & $0.0089 * * *$ \\
\hline d(Lntracg does not Granger Cause d(Lnsupigm) & & 7.23016 & 0.0618 \\
\hline d(Lnsupcot) does not Granger Cause d(Lntracg) & 54 & 1.44937 & $0.0030 * *$ \\
\hline d(Lntracg) does not Granger Cause d(Lnsupcot) & & 1.71010 & $0.0019 * *$ \\
\hline d(Lnsupma) does not Granger Cause d(Lntracg) & 54 & 0.81470 & $0.00489 * *$ \\
\hline d(Lntracg )does not Granger Cause d(Lnsupma) & & 3.59824 & $0.0352 * *$ \\
\hline $\mathrm{d}($ Lnsupmc) does not Granger Cause d(Lntracg) & 54 & 0.68287 & $0.0001 * * *$ \\
\hline $\mathrm{d}($ Lntracg) does not Granger Cause d(Lnsupmc) & & 9.76392 & $0.0003^{* * *}$ \\
\hline d(Lnsuprz )does not Granger Cause d(Lntracg) & 54 & 4.02453 & $0.0244 * *$ \\
\hline d(Lntracg) does not Granger Cause d(Lnsuprz) & & 3.39161 & 0.421 \\
\hline d(Lnsupmil) does not Granger Cause d(Lntracg) & 54 & 0.00023 & $0.0019 * *$ \\
\hline d(Lntracg) does not Granger Cause d(Lnsupmil) & & 1.93734 & 0.1554 \\
\hline $\mathrm{d}($ Lnsupcot $)$ does not Granger Cause d(Lnsupigm) & 54 & 0.42846 & 0.6540 \\
\hline $\mathrm{d}($ Lnsupigm) does not Granger Cause d(Lnsupcot) & & 1.64817 & 0.2033 \\
\hline d(Lnsupma) does not Granger Cause d(Lnsupigm) & 54 & 0.29194 & 0.7482 \\
\hline d(Lnsupigm) does not Granger Cause d(Lnsupma) & & 1.59345 & 0.2140 \\
\hline d(Lnsupmc) does not Granger Cause d(Lnsupigm) & 54 & 1.37541 & 0.2627 \\
\hline d(Lnsupigm) does not Granger Cause d(Lnsupmc) & & 0.49174 & 0.6147 \\
\hline d(Lnsupma) does not Granger Cause d(Lnsupigm) & 54 & 0.29194 & 0.7482 \\
\hline d(Lnsupigm) does not Granger Cause d(Lnsupma) & & 1.59345 & 0.2140 \\
\hline d(Lnsuprz) does not Granger Cause d(Lnsupigm) & 54 & 1.57823 & 0.2171 \\
\hline d(Lnsupigm) does not Granger Cause d(Lnsuprz) & & 1.90082 & 0.1608 \\
\hline d(Lnsupmil) does not Granger Cause d(Lnsupigm) & 54 & 0.06205 & 0.9399 \\
\hline d(Lnsupigm) does not Granger Cause d(Lnsupmil) & & 0.64371 & 0.5299 \\
\hline d(Lnsuprz) does not Granger Cause d(Lnsupcot) & 54 & 1.79510 & 0.1773 \\
\hline $\mathrm{d}($ Lnsupcot $)$ does not Granger Cause d(Lnsuprz) & & 2.13179 & 0.1300 \\
\hline d(Lnsupmil) does not Granger Cause d(Lnsupigm) & 54 & 0.06205 & 0.9399 \\
\hline d(Lnsupigm) does not Granger Cause d(Lnsupmil) & & 0.64371 & 0.5299 \\
\hline d(Lnsupmil) does not Granger Cause d(Lnsupcot) & 54 & 0.98698 & 0.3803 \\
\hline d(Lnsupcot ) does not Granger Cause d(Lnsupmil) & & 7.57091 & $0.0014 * * *$ \\
\hline d(Lnsupmc) does not Granger Cause d(Lnsupma) & 54 & 0.90094 & 0.4131 \\
\hline d(Lnsupma) does not Granger Cause d(Lnsupmc) & & 10.6752 & $0.0002 * * *$ \\
\hline d(Lnsuprz) does not Granger Cause d(Lnsupma) & 54 & 7.13301 & $0.0020 * * *$ \\
\hline d(Lnsupma) does not Granger Cause d(Lnsuprz) & & 1.26155 & 0.2926 \\
\hline d(Lnsupmil) does not Granger Cause d(Lnsupma) & 54 & 0.11288 & 0.8935 \\
\hline d(Lnsupma) does not Granger Cause d(Lnsupmil) & & 1.82345 & 0.1727 \\
\hline d(Lnsupmil) does not Granger Cause d(Lnsupmc) & 54 & 7.83174 & $0.0012 * * *$ \\
\hline d(Lnsupmc) does not Granger Cause d(Lnsupmil) & & 3.08603 & $0.0550 *$ \\
\hline d(Lnsupmil) does not Granger Cause d(Lnsupmc) & 54 & 1.31845 & 0.2773 \\
\hline d(Lnsupmc) does not Granger Cause d(Lnsupmil) & & 3.92266 & $0.0266^{* *}$ \\
\hline d(Lnsupmil) does not Granger Cause d(Lnsuprz) & 54 & 3.52337 & $0.0375^{* *}$ \\
\hline $\mathrm{d}($ Lnsuprz) does not Granger Cause d(Lnsupmil) & & 1.54148 & 0.2247 \\
\hline
\end{tabular}

** Significant at the 5\% significance level 
Table 6. Correlation matrix

\begin{tabular}{lccccccc}
\hline Variables & $d($ Lnsupigm $)$ & $d($ Lnsupcot $)$ & $d($ Lnsupma $)$ & $d($ Lnsupmc $)$ & $d($ Lnsuprz $)$ & $d($ Lnsupmil $)$ & $d($ Lntracg $)$ \\
\hline $\mathrm{d}($ Lnsupigm) & 1.000000 & 0.035034 & 0.017182 & -0.045321 & 0.075409 & -0.057174 & $0.9116^{* *}$ \\
$\mathrm{~d}($ Lnsupcot $)$ & & 1.000000 & $0.8964^{* *}$ & $0.08592^{* *}$ & -0.091367 & 0.352346 & 0.0041 \\
$\mathrm{~d}($ Lnsupma) & & & 1.000000 & 0.017783 & -0.226257 & -0.034030 & 0.0045 \\
$\mathrm{~d}($ Lnsupmc) & & & & 1.000000 & -0.019356 & -0.076366 & 0.00315 \\
$\mathrm{~d}($ Lnsuprz) & & & & & 1.000000 & -0.072481 & $0.8325^{* *}$ \\
$\mathrm{~d}($ Lnsupmil) & & & & & & 1.000000 & $0.0815^{* *}$ \\
$\mathrm{~d}($ Lntracg) & & & & & & & 1.000000 \\
\hline
\end{tabular}

** Significant at the $5 \%$ significance level

The estimation results include the estimation of the cointegration vector, i.e. the long-term relationship, and the estimation of the coefficients of the adjustment or short-term equations. These results are shown in Table 7 . The coefficients for the areas planted of cotton (lsupcot), maize (lnsupma) and cassava (Insupmc) are not significant at the 5\% threshold in the long-run relationship, and the Student's statistic is - 0.645 . The other coefficients are significant, the areas planted of millet (lnsupmils), paddy rice (lnsupriz) and yam (lnsupigm). These areas planted have positive and significant coefficients, they are worth respectively: $0.1356 ; 0.4297$ and 0.5885 . Thus, over the long run, an increase in the area planted of millet (Insupmils), paddy rice (Insupriz) and yam (lnsupigm) by 10 points leads to an increase of 1.356, 4.297 and 5.885, respectively in agricultural tractors, ceteris paribus.

In Table 8 CointEq1 denotes the vector associated with the cointegration relation containing coefficients of the error correction terms. Its coefficients translate the speed of adjustment from the short run towards the long-run equilibrium. The coefficients of the restoring forces relating to the number of agricultural tractors (lntracg) and the land uses of cotton (lnsupcot), maize (lnsupma) and cassava (lnsupmc) are positive, these results which may seem surprising insofar as in Benin, cotton benefits more from material and financial state support on the one hand and the backward effects of cotton are captured by maize and cassava on the other hand. The other coefficients of return to long-run equilibrium are negative, which reflects a return to the long-term equilibrium. Short-term dynamics show that the number of agricultural tractors is influenced by one-year and two-years lagged paddy area, with respective elasticities of -0.27 and -0.21 . Similarly, this short-term dynamics also indicates that the number of agricultural tractors is influenced by one-year and two-years lagged milled land use, with elasticities of -0.34 and -0.09 . Finally, this same short-term dynamic also shows that the number of agricultural tractors impacts one-year and two-years lagged yams land use, with respective elasticities of -0.9 and -0.47 . This short-term dynamic is confirmed by the Granger causality tests (Table 5).

The error correction model used to measure the impact of the number of agricultural tractors on the areas planted of cotton (lnsupcot), maize (lnsupma), cassava (lnsupmc), millet (lnsupmils), paddy rice (lnsupriz) and yam (lnsupigm) in Benin during the period from 1961 to 2016 show a weak causal structure between the different areas planted. At the significance level of 5\%, there is basically no causal relationship between the areas planted of cotton (lnsupcot), maize (Insupma), cassava (lnsupmc) and the number of tractors. These surprising results show that although cotton contributes more to the formation of agricultural growth in Benin, agricultural mechanization remains far from being a reality. The problem of adopting agricultural mechanical innovations is acute.

Table 7. Cointegration vector

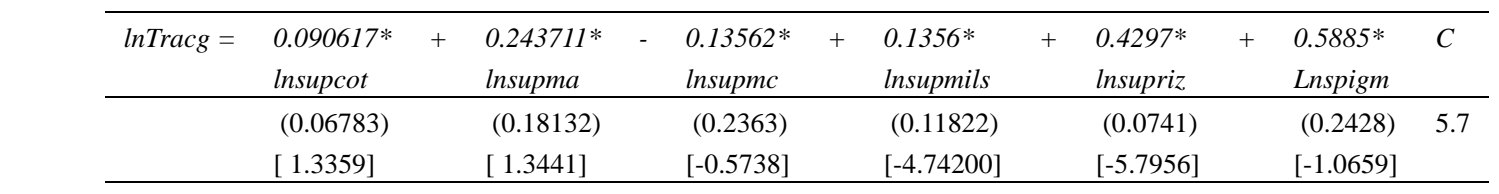

Standard errors in ( ). t-student in [ ] 
Table 8. Coefficients of the short-run dynamics

\begin{tabular}{|c|c|c|c|c|c|c|c|}
\hline Error Correction & $d($ Lntracg $)$ & $d($ Lnsupcot $)$ & $d($ Lnsupma $)$ & $d($ Lnsupmc $)$ & $d($ Lnsuprz $)$ & $d($ Lnsupmil $)$ & $d($ Lnsupigm $)$ \\
\hline \multirow[t]{3}{*}{ CointEq1 } & -0.647239 & -0.577014 & -0.038211 & -0.437358 & 0.698915 & 0.069883 & 0.112596 \\
\hline & $(0.20037)$ & $(0.29226)$ & $(0.13448)$ & $(0.16616)$ & $(0.25609)$ & $(0.18085)$ & $(0.15408)$ \\
\hline & [3.23027] & [ - 1.97429$]$ & [ -0.28414$]$ & {$[-2.63222]$} & [ 2.72914] & [ 0.38643$]$ & [ 0.73076$]$ \\
\hline \multirow[t]{3}{*}{$\mathrm{d}($ Lntracg) $)(-1)$} & -0.155508 & -0.200441 & -0.012616 & -0.136607 & -0.595928 & 0.280010 & -0.305966 \\
\hline & $(0.22309)$ & $(0.32541)$ & $(0.14973)$ & $(0.18500)$ & $(0.28514)$ & $(0.20136)$ & $(0.17155)$ \\
\hline & {$[-0.69706]$} & {$[-0.61596]$} & {$[-0.08426]$} & {$[-0.73842]$} & {$[-2.08997]$} & [ 1.39063$]$ & {$[-1.78349]$} \\
\hline \multirow[t]{4}{*}{$\mathrm{d}($ Lntracg) $)(-2)$} & -0.039371 & -0.088905 & 0.106864 & 0.171254 & -0.533492 & 0.438005 & -0.049343 \\
\hline & (0.17949) & $(0.26181)$ & $(0.12047)$ & $(0.14884)$ & $(0.22941)$ & $(0.16200)$ & $(0.13802)$ \\
\hline & {$[-0.21935]$} & {$[-0.33958]$} & [ 0.88709] & [ 1.15058$]$ & {$[-2.32552]$} & [ 2.70372] & {$[-0.35749]$} \\
\hline & 0.086945 & 0.008637 & -0.076225 & -0.142423 & -0.163438 & -0.045735 & 0.009784 \\
\hline \multirow[t]{2}{*}{$\mathrm{d}($ Lnsupcot)(-1) } & $(0.11560)$ & $(0.16862)$ & $(0.07759)$ & $(0.09586)$ & $(0.14775)$ & $(0.10434)$ & $(0.08890)$ \\
\hline & {$[-0.75211]$} & [ 0.05122$]$ & [-0.98244] & {$[-1.48570]$} & {$[-1.10617]$} & {$[-0.43833]$} & [ 0.11006$]$ \\
\hline \multirow[t]{3}{*}{ d(Lnsupcot)(-2) } & 0.389124 & -0.079188 & -0.036582 & -0.065119 & 0.083415 & -0.023471 & -0.049401 \\
\hline & (0.11693) & $(0.17056)$ & $(0.07848)$ & $(0.09697)$ & $(0.14945)$ & $(0.10554)$ & $(0.08992)$ \\
\hline & [ 3.32780$]$ & {$[-0.46428]$} & {$[-0.46613]$} & {$[-0.67157]$} & [ 0.55814$]$ & [-0.22239] & [-0.54939] \\
\hline \multirow[t]{3}{*}{$\mathrm{d}($ Lnsupma)(-1) } & 0.156391 & -0.305125 & -0.266541 & -0.038219 & 0.555520 & -0.221127 & 0.125701 \\
\hline & (0.30118) & $(0.43931)$ & $(0.20214)$ & $(0.24975)$ & $(0.38494)$ & $(0.27184)$ & $(0.23160)$ \\
\hline & [ 0.51926$]$ & {$[-0.69455]$} & [-1.31859] & {$[-0.15303]$} & [ 1.44312] & {$[-0.81346]$} & [ 0.54274$]$ \\
\hline \multirow[t]{3}{*}{ d(Lnsupma)(-2) } & -0.023713 & -0.601999 & -0.422628 & -0.388748 & 0.054637 & -0.165505 & 0.210485 \\
\hline & $(0.28769)$ & $(0.41964)$ & (0.19309) & $(0.23857)$ & $(0.36770)$ & $(0.25966)$ & $(0.22123)$ \\
\hline & {$[-0.08243]$} & [-1.43457] & {$[-2.18881]$} & {$[-1.62951]$} & [ 0.14859] & [-0.63739] & [ 0.95143$]$ \\
\hline \multirow[t]{3}{*}{$\mathrm{d}($ Lnsupmc)(-1) } & 0.126107 & -0.500505 & 0.024339 & -0.022685 & -0.356933 & 0.169167 & -0.003841 \\
\hline & $(0.26841)$ & $(0.39152)$ & $(0.18015)$ & $(0.22258)$ & $(0.34306)$ & $(0.24226)$ & $(0.20641)$ \\
\hline & [ 0.46983$]$ & [ 1.27837$]$ & {$[0.13510]$} & {$[-0.10192]$} & {$[-1.04043]$} & [ 0.69828$]$ & {$[-0.01861]$} \\
\hline \multirow[t]{3}{*}{ d(Lnsupmc)(-2) } & 0.161708 & 0.648725 & 0.183830 & 0.068870 & 0.271960 & 0.090022 & -0.300846 \\
\hline & $(0.23793)$ & $(0.34706)$ & (0.15969) & $(0.19731)$ & $(0.30411)$ & $(0.21475)$ & $(0.18297)$ \\
\hline & [ 0.67963$]$ & [ 1.86920$]$ & [ 1.15115$]$ & [ 0.34905$]$ & [ 0.89429] & [ 0.41919] & {$[-1.64425]$} \\
\hline \multirow[t]{3}{*}{ d(Lnsuprz)(-1) } & -0.270894 & -0.483329 & -0.218936 & 0.094273 & --0.116515 & 0.126114 & 0.055970 \\
\hline & $(0.18946)$ & $(0.27636)$ & $(0.12716)$ & $(0.15711)$ & $(0.24216)$ & $(0.17100)$ & $(0.14570)$ \\
\hline & {$[-1.42980]$} & [-1.74891] & [-1.72173] & [ 0.60003$]$ & {$[-0.48115]$} & [ 0.73749] & [ 0.38415$]$ \\
\hline \multirow[t]{3}{*}{ d(Lnsuprz)(-2) } & -0.213323 & 0.126092 & 0.132552 & 0.099354 & 0.218316 & 0.061417 & 0.098621 \\
\hline & $(0.18114)$ & $(0.26422)$ & $(0.12158)$ & $(0.15021)$ & $(0.23152)$ & (0.16349) & (0.13930) \\
\hline & {$[-1.17765]$} & [ 0.47722] & [ 1.09028] & [ 0.66142] & [ 0.94296] & [ 0.37565$]$ & [ 0.70799] \\
\hline \multirow[t]{4}{*}{ d(Lnsupmil)(-1) } & -0.121988 & -0.031955 & 0.085291 & 0.089607 & 0.419768 & -0.087572 & 0.004545 \\
\hline & $(0.13052)$ & (0.19038) & $(0.08760)$ & $(0.10823)$ & $(0.16682)$ & $(0.11780)$ & $(0.10037)$ \\
\hline & {$[-0.93465]$} & {$[-0.16785]$} & [ 0.97366$]$ & [ 0.82791$]$ & [ 2.51633] & [-0.74339] & [ 0.04528$]$ \\
\hline & -0.349412 & -0.042756 & -0.086420 & 0.039017 & -0.435080 & 0.134465 & 0.068142 \\
\hline \multirow[t]{2}{*}{ d(Lnsupmil)(-2) } & (0.11823) & $(0.17246)$ & $(0.07935)$ & $(0.09804)$ & $(0.15112)$ & $(0.10671)$ & $(0.09092)$ \\
\hline & {$[-2.95530]$} & [-0.24792] & [-1.08906] & [ 0.39795] & {$[-2.87912]$} & [ 1.26006$]$ & [ 0.74947] \\
\hline \multirow[t]{3}{*}{ d(Lnsupigm)(-1) } & -0.93679 & -0.322457 & 0.235144 & 0.340385 & -0.318617 & 0.165048 & -0.597375 \\
\hline & $(0.23778)$ & $(0.34684)$ & (0.15959) & $(0.19718)$ & $(0.30391)$ & $(0.21461)$ & $(0.18285)$ \\
\hline & [ -0.39397] & {$[-0.92971]$} & [ 1.47344] & [ 1.72626$]$ & [-1.04839] & [ 0.76905$]$ & {$[-3.26701]$} \\
\hline \multirow[t]{6}{*}{ d(Lnsupigm) (-2) } & -0.47073 & -0.499944 & -0.154252 & -0.290802 & -0.521875 & 0.108914 & -0.309225 \\
\hline & $(0.23304)$ & (0.33992) & $(0.15641)$ & $(0.19325)$ & $(0.29786)$ & $(0.21034)$ & $(0.17921)$ \\
\hline & {$[-0.63111]$} & {$[-1.47075]$} & {$[-0.98622]$} & [-1.50479] & {$[-1.75211]$} & [ 0.51781$]$ & {$[-1.72552]$} \\
\hline & 0.055255 & 0.098784 & 0.032227 & 0.024501 & 0.042856 & 0.033457 & 0.022483 \\
\hline & $(0.03180)$ & $(0.04638)$ & $(0.02134)$ & $(0.02637)$ & $(0.04064)$ & $(0.02870)$ & $(0.02445)$ \\
\hline & [ 1.73770$]$ & [ 2.12979] & [ 1.51006$]$ & [ 0.92918$]$ & [ 1.05447$]$ & [ 1.16576$]$ & [ 0.91944$]$ \\
\hline
\end{tabular}

Standard errors in ( ). T-student in [ ]

Moreover, the hypothesis of a transfer of labor from agriculture to the industrial sector is difficult to observe in Benin. On the one hand, the industrial sector is not structurally able to absorb the underemployed labor force in the agricultural sector. On the other hand, this workforce is not sufficiently qualified. The transfer of labor is then to the informal sector with the phenomenon of rural exodus. In recent years, there has been a growing trend of the informal sector in the Beninese economy with the proximity of Nigeria. Agricultural mechanization, by its expansion, can induce sustainable agricultural growth, reduce poverty, unemployment, rural exodus and improve food security. Agricultural mechanization can also lead to the development of other sectors such as agribusiness, tourism and trade. Since the independence in 1960, the Beninese government has always put agriculture at the epicenter of economic development. During the five-year plans, Beninese farmers were not in some way accompanied by mechanization. The government is still advocating for the valorization of agricultural sectors. Although Beninese agriculture is family-oriented, it does not even benefit from small mechanization. The 
income derived from this family farming is not meant to finance the development of the industrial sector, more able to set up real conditions for economic development, and at the same time, the share of the agricultural sector in the GDP was doomed to decline as theories of development predict. The reasons given in the literature point to many problems, including the mismanagement of agricultural investments.

\section{Conclusion}

The objective of this article was to evaluate the impact of agricultural mechanization on land uses in Benin. Agricultural mechanization in Benin is far from being effective. Despite the fact that cotton production benefits from numerous physical and financial support from the State, this production seems not to have actually benefited from effective agricultural mechanization. The cotton sub-sector has always been at the center of Benin's economic policy. This agricultural sub-sector has undergone changes throughout Benin's history, with since 1990 a redefinition of the roles played by the various actors in this agricultural sub-sector that has never led to mechanization. This agricultural subsector is still slow to have a ripple effect in order to start a real economic take-off because of the real non-existence of mechanization. Estimates using data on the number of agricultural tractors and areas planted of cotton, maize, cassava, paddy rice, millet and yams in Benin show that there is a long-run relationship only between the number of agricultural machinery and the areas planted of paddy rice, millet and yams. Thus, agricultural mechanization in Benin has evolved in certain stability at the level of agricultural policy. This long-term relationship shows that an increase in the area planted of cotton, maize and cassava leads to a drop in the number of agricultural tractors. Estimates also show that the development of agricultural mechanization has not caused the land uses of cotton, maize and cassava. These results can be explained on the one hand by the traditional character of agricultural activity in Benin, the agricultural sector is still slow to modernize completely. On the other hand, the agricultural economy is still relatively disjointed. We could add external factors. The producers are price takers on the world market, so there is a risk of losses linked to the drop in commodity prices, as was the case in the early 1980s. These various results lead to a few recommendations: Strengthen the link between agricultural mechanization and sustainable agriculture. This reinforcement can be effective if and only if substantial agricultural public investments are spent in agriculture accompanied by training and adequate research in order to boost a sustainable green revolution. Economic theory shows this necessity and many empirical examples provide an illustration. For the Beninese authorities, many measures are needed: there is a need to promote greater local processing of commodities. This proposal is not original, it has been mentioned for decades in Benin's economic analyzes. The transformation of commodities adds more value to the products, and thus increases the wealth created. At the same time, there is job creation. The export of raw commodities contributes to the deterioration of the terms of trade. The food industry is one of the industries using agricultural products. Food imports have greatly increased in Benin. Incentives must be put in place to allow the development of local agro-industries using raw materials from the agricultural sector. With the boom of agribusiness, the demand structure for agriculture would be modified so that the agricultural sector would serve as an upstream sector for other sectors.

\section{References}

Campagne, P. (1989). Mécanisation et motorisation des exploitations Agricoles: Quelques questions économiques. Les Cahiers de la Recherche Développement, 23, 65-77.

FAO/ONUDO (2008). La mécanisation de l'agriculture en Afrique... Il est temps d'agir. Rapport d'un comité d'experts. Programmer des investissements pour accroître la productivité agricole, $27 \mathrm{p}$

FAO (2008a). Agricultural mechanization in sub-Saharan Africa: time for a new look (La mécanisation agricole en Afrique subsaharienne: une nouvelle perspective). Mrema, G., Baker, D. et Kahan, D. Organisation des Nations unies pour l'alimentation et l'agriculture. Rome, Italie. Document occasionnel de gestion, commercialisation et finances agricoles $\mathrm{n}^{\circ} 22.54 \mathrm{pp}$.

FAO (2008). Guide de formulation d'une stratégie de mécanisation agricole Etude de cas: stratégie nationale de la mécanisation agricole au Mali. Documents de travail sur le génie rural et alimentaire, 7, 50.

Retrieved from http://www.fao.org/fileadmin/user_upload/ags/publications/AGST_WD_7.pdf.

FAO (2014). AGP-Mécanisation Agricolahome. Retrieved from

Http:www.fao.org/agriculture/crops/planthematique-du-site/theme/spi/mecanisation-agricole/mecanisationagricole-home/fr/

FAO (2011). Investment in agricultural mechanization in Africa: Conclusions and recommandations of a Round Table Meeting of Experts (L'investissement dans la mécanisation agricole en Afrique: conclusions et recommandations d'une table ronde d'experts). Ashburner, J.E. et Kienzle, J., éd. Organisation des Nations 
unies pour l'alimentation et l'agriculture. Rome, Italie. Rapport technique sur le génie rural et alimentaire $\mathrm{n}^{\circ}$ 8. 76 pp. ISBN: 978-92-5-1068208-5

FAO (2013a). Agricultural mechanization in India (La mécanisation agricole en Inde). Singh, G. In: Kienzle, J., Ashburner, J. et Sims, B.G. (éd.). Mechanization for rural development: a review of patterns and progress from around the world (La mécanisation pour le développement rural: examen des modèles et des avancées dans le monde). Organisation des Nations unies pour l'alimentation et l'agriculture. Rome, Italie. Integrated crop management 20: 99-119.

FAO (2013b). China: development of farm mechanization and the agricultural machinery industry (Chine: le développement de la mécanisation agricole et l'industrie des machines agricoles). Wang, M. In: Kienzle, J., Ashburner, J. et Sims, B.G. (éd.). Mechanization for rural development: a review of patterns and progress from around the world (La mécanisation pour le développement rural: examen des modèles et des avancées dans le monde). Organisation des Nations unies pour l'alimentation et l'agriculture. Rome, Italie. Integrated crop management 20: 121-139.

Gollin, D., Morris, M., \& Byerlee, D. (2005). Technology adoption in intensive post-green revolution systems (L'adoption de la technologie dans les systèmes intensifs postérieurs à la révolution verte). Amer. J. Agr. Econ., 87(5), 1310-1316. https://doi.org/10.1111/j.1467-8276.2005.00824.x

Havard, M., \& Mbengue, H. M. (1988). Une réflexion insuffisante sur les orientations de la mécanisation au Sénégal. Quelques exemples concrets, CIRAD / MESRU-Economie de la Mécanisation en Région Chaude-Montpellier

Hazell, P. B. R. (2008). An assessment of the impact of agricultural research in South Asia since the green revolution (Évaluation de l'impact de la recherche agricole en Asie du Sud depuis la révolution verte). Rome. Science Council Secretariat.

MAEP (2014). Rapport d'évaluation à mi-parcours du plan stratégique de relance du secteur agricole. Cotonou : DPP/MAEP, $88 \mathrm{p}$.

MAEP (2015). Statistiques agricoles. Cotonou : DPP/MAEP.

ONASA (2016). Evaluation de la Production Vivrière 2015 et des Perspectives Alimentaires pour 2016 au Bénin. Rapport par Département Volume 2.

PPMA (2015). Evaluation de la production vivrière 2015 et des perspectives alimentaire pour 2016 au Bénin. Rapport Général, 1. PPMA-MAEAP-ONASA-DSVSA-SSA

Royal Society (2009). Reaping the benefits: Science and the sustainable intensification of global agriculture (Récolter les fruits de nos efforts: la science et l'intensification durable de l'agriculture mondiale). RS Policy document 11/09. Londres.

Sims, B. G., \& Kienzle, J. (2015). Rural mechanisation: where are we now and where should we be going? (La mécanisation rurale: où en sommes-nous et où devons-nous aller?). Rural, 2149(2), 6-9.

Titman, D. (1998). The greening of the green revolution (Le verdissement de la révolution Verte). Nature, 396, 211-212. https://doi.org/10.1038/24254

Yurdakul, O. (1994). Les développements comparés de l'agriculture turque. In : Dupuy B. (comp.), Dupuy B. (collab.). Equilibre alimentaire, agriculture et environnement en Méditerranée. Montpellier : CIHEAM. pp. 85-107 (Options Méditerranéennes: Série A. Séminaires Méditerranéens; n. 24). Retrieved from http://om.ciheam.org/om/pdf/a24/CI950050.pdf

\section{Notes}

Note 1 . At least $10 \%$ of budget must be allocated to agriculture.

Note 2. Patrice Cokou Kpade et Jean-Pierre Boinon, 2011. «Dynamique des politiques cotonnières au Bénin. Une lecture par la dépendance de sentier », Économie rurale, 321, 58-72.

Note 3. Banque mondiale, (2012), African Development Indicators sur l'économie Béninoise, Base de données.

\section{Copyrights}

Copyright for this article is retained by the author(s), with first publication rights granted to the journal.

This is an open-access article distributed under the terms and conditions of the Creative Commons Attribution license (http://creativecommons.org/licenses/by/3.0/). 